REFLEXIONES CRÍTICAS SOBRE LOS ABORDAJES TEÓRICOMETODOLÓGICOS EN LA ARQUEOLOGÍA DE BUQUES DE GUERRA Y CAMPOS DE BATALLA ACUÁTICOS

CRITICAL THOUGHTS ON THEORETICAL AND METHODOLOGICAL APPROACHES TO THE ARCHAEOLOGY OF WARSHIPS AND ACUATIC BATTLEFIELDS

Ricardo Borrero Londoño

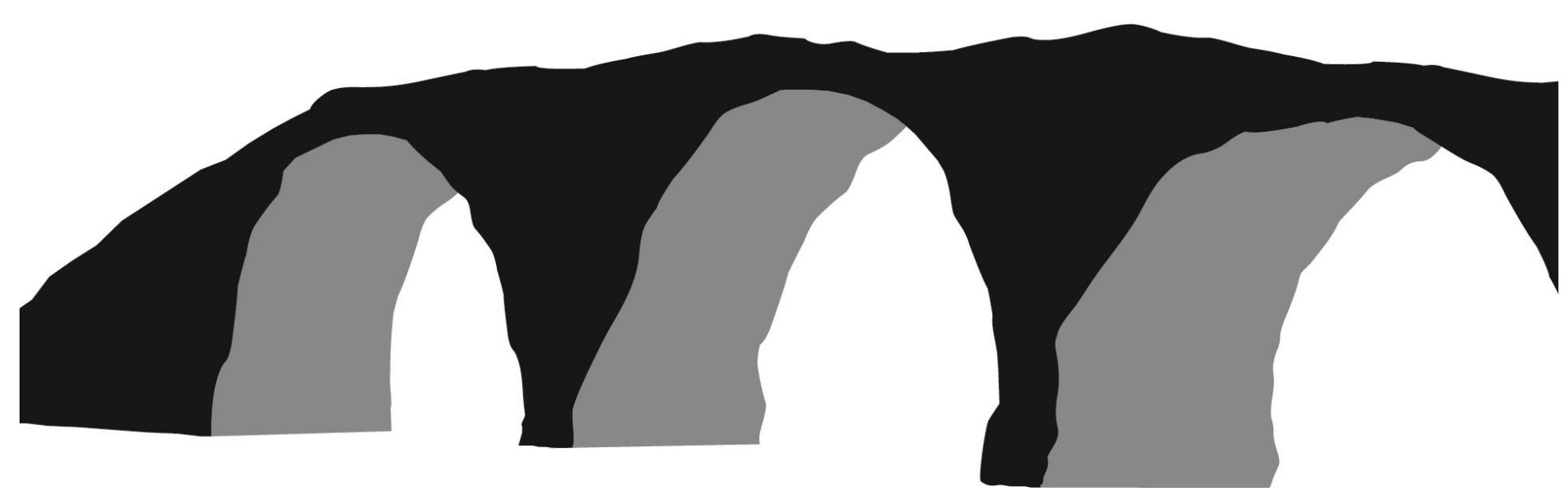




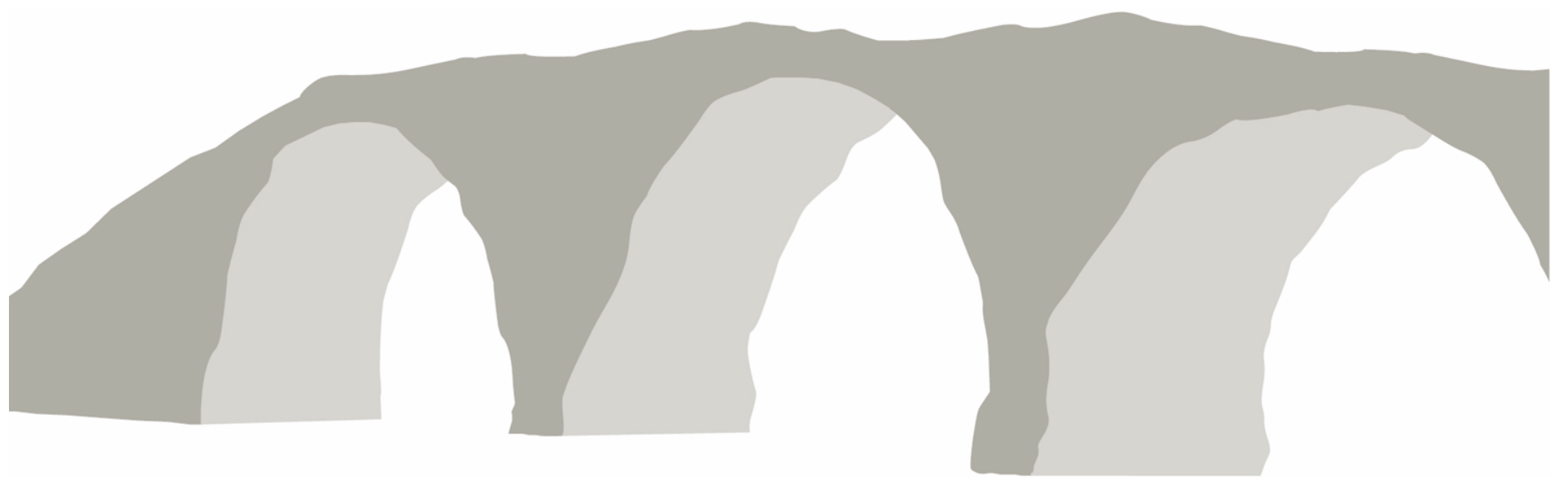

Data de recebimento: 05/10/2017.

Data de aceite: 26/04/2018. 


\title{
REFLEXIONES CRÍTICAS SOBRE LOS ABORDAJES TEÓRICO- METODOLÓGICOS EN LA ARQUEOLOGÍA DE BUQUES DE GUERRA Y CAMPOS DE BATALLA ACUÁTICOS
}

\section{CRITICAL THOUGHTS ON THEORETICAL AND METHODOLOGICAL APPROACHES TO THE ARCHAEOLOGY OF WARSHIPS AND ACUATIC BATTLEFIELDS}

\author{
Ricardo Borrero Londoño ${ }^{1}$
}

\begin{abstract}
RESUMEN
Este artículo tiene por objetivo la revisión crítica de los abordajes teórico-metodológicos en la arqueología de navíos de guerra y campos de batalla acuáticos. A través de ejemplos de investigaciones llevadas a cabo desde sus tres principales corrientes (particularismo histórico-cultural, procesualismo y postprocesualismo), se analizan las posibilidades, límites y desafíos que cada una presenta. Se propone que el camino más productivo consiste en efectuar una síntesis que tome elementos de cada una de las posturas que se exploran.
\end{abstract}

Palabras clave: naufragios, navíos de guerra, campos de batalla, particularismo histórico-cultural, procesualismo, postprocesualismo.

RESUMO

Este artigo tem como escopo fazer uma revisão crítica das abordagens teórico-metodológicas na arqueologia de navios de guerra e campos de batalha aquáticos. Através de exemplos de pesquisas feitas desde suas três principais correntes (particularismo histórico-cultural, processualismo e pós-processualismo), são analisadas as possibilidades, limites e desafios que cada uma apresenta. A proposta é que o caminho mais produtivo consiste em efetuar uma síntese que tome elementos de cada uma das posturas expostas.

Palavras-chave: naufrágios, navios de guerra, campos de batalha, particularismo histórico-cultural, processualismo, pós-processualismo.

\footnotetext{
${ }^{1}$ Estudiante de doctrado. Laboratorio de Reconstrucción de Embarcaciones J. Richard Steffy, Programa de Arqueología Náutica (NAP), Departamento de Antropología, Universidad de Texas A\&M. Harvey Rd. 1001, Apt. 43, College Station, TX 77840. ricardoborrero373@gmail.com.
} 


\begin{abstract}
This paper is a critical review of the theoretical and methodological approaches to the archaeology of war vessels and aquatic battlefields. It analyses the possibilities, limitations and challenges through examples of the three principal currents (culture-historical particularism, procesualism and post-processualism), and proposes that the most productive path consists in a synthesis encompassing elements of each of the explored paradigms.
\end{abstract}

Keywords: shipwreck, warships, battlefields, culture-historical particularism, procesualism, postprocessualism. 
...la arqueología de muchos barcos post-medievales ha tendido a ser introspectiva y particularista, sus promotores con frecuencia han fallado en ver más allá de la inmediatez de sus descubrimientos. Esto ha ocasionado intensos debates con aquéllos que abogan por una aproximación más amplia y teóricamente orientada, antropológica en su metodología y nomotécnica en sus metas (...) siempre emerge un consenso profeso entre los particularistas y los generalistas, a tal punto que ambos campos, al aproximarse a su investigación desde diferentes perspectivas, usualmente, persiguen objetivos semejantes y alcanzan resultados comparables (Colin Martin, 2001:397).

Muchos arqueólogos históricos trabajando tanto en contextos terrestres como acuáticos, continúan prefiriendo enfoques descriptivos y particularistas que se concentran en las características singulares del período y el lugar que estudian. La perspectiva histórico particularista no está errada. Todos los arqueólogos marítimos y subacuáticos necesitan alcanzar una perspectiva histórica detallada y "densa" de sus materiales de la misma manera que sus colegas más orientados por los textos. Pero una perspectiva estrictamente histórico particularista es también inadecuada, especialmente cuando se trata de evaluar resultados arqueológicos. En la arqueología subacuática, la comprobación de hipótesis generalizantes, la búsqueda de principios generales y el particularismo histórico son complementarios (Richard Gould, 2011: 3).

\section{INTRODUCCIÓN}

Este trabajo tiene por objetivo efectuar una revisión crítica de la literatura sobre los pecios de naves de guerra y campos de batalla acuáticos. Se divide en cuatro secciones: 1) una introducción que contiene las definiciones de los principales conceptos a emplear; 2) un vistazo al estado del arte general con énfasis en los trabajos arqueológicos realizados en América Latina ; 3) una sección de historia y teoría que cubre las perspectivas histórico-cultural, procesual y postprocesual en el estudio de naufragios de guerra y paisajes bélicos; y 4) una conclusión en que se refuerzan y resumen los argumentos principales esgrimidos en el texto, y se plantea que el camino más productivo para la arqueología de los buques de guerra y los campos de batalla acuáticos consiste en elaborar una síntesis que tome los elementos más significativos de cada corriente teórico-metodológica.

Los trabajos reseñados fueron seleccionados por tratarse de aquellas contribuciones con que mejor puede ejemplificarse cada paradigma, aunque a veces las fronteras entre uno y otro resultan difusas. En su gran mayoría, los textos fueron elegidos por tratarse de aportaciones que, pese a su importancia, por haber sido escritas en inglés, han tenido escasa resonancia en la academia latinoamericana hasta la fecha. Se mencionan también algunos de las investigaciones más notables que han tenido lugar en buques de guerra y campos de batalla acuáticos en América Latina. Estas últimas son particularmente difíciles de clasificar, pues han seguido una senda teórica propia, no necesariamente equivalente a la de las contribuciones del mundo anglosajón. Las publicaciones traídas a colación distan de agotar el amplio espectro del estado del arte global. Selecciones más comprensivas pueden hallarse en las publicaciones Lost Warships: An Archaeological Tour of War at Sea de James P. Delgado (2001); The Archaeology of Ships of War y Excavating Ships of War, editados por Mensun Bound (1995, 1998). Un panorama más completo y detallado de la arqueología de campos de batalla en Latinoamérica fue publicado por Landa en el año 2013.

Se entiende por buque de guerra aquel que fue diseñado y construido específicamente con un propósito bélico. Tales naves se diferencian de aquellas construidas para el transporte de personas (barco de pasajeros) y mercancías (buque mercante), u otras con fines diferentes de la guerra (buques de investigación, de 
salvamento, etc.). Comunmente los buques de guerra están artillados, suelen ser más rápidos, maniobrables y resistentes al daño inflingido. Antes de la invención de los navíos de línea, la diferenciación por propósito resulta un poco vaga. Especialmente en situaciones de conflicto, cuando sin importar el propósito con el cual fueron concebidas, las naves pueden tomarse y muchas veces artillarse para ser puestas al servicio de la guerra. Hasta finales del siglo XVII, fueron comunes las naves de propósito múltiple, como los galeones que solían servir para el transporte de metales y simultáneamente se protegían mediante piezas de artillería y un diseño especial.

Una síntesis de los principios de la arqueología de campos de batalla terrestres fue escrita en los países británicos por Sutherland \& Holst en 2005. Ésta inicia con la discusión acerca de la definición de la arqueología de campos de batalla. Esta etiqueta engloba la arqueología de conflictos pretéritos. Como su tema es el evento de la batalla y no el escenario en el cual tiene lugar, el término "campo" es confuso en cierto sentido y algunos académicos prefieren denominarla arqueología de la batalla. En la medida en que este tipo de arqueología es aplicable a la investigación de períodos de inestabilidad civil, el descriptor arqueología del conflicto resulta aún más apropiado e inclusivo (Sutherland \& Holst, 2005: 1-2). Scott \& McFeaters (2011) también hacen referencia a la definición de la arqueología del conflicto y los campos de batalla, y coinciden en que la primera forma es más inclusiva y ofrece una perspectiva más amplia, en la medida en que exhorta a los estudiosos a considerar decisiones y consecuencias que tienen lugar más allá de los confines del campo de batalla. Acorde con Broadwater (2011: 177, traducido por el autor) “...las batallas navales solo pueden ser plenamente interpretadas y sólo se les puede conferir sentido histórico, al estudiarlas como eventos individuales enmarcados en un contexto más amplio en el que otros eventos naturales, militares y políticos estaban teniendo lugar".

El arqueólogo checoslovaco Slavomil Vencl (1984) también afirma que la arqueología del conflicto debe ir más allá del registro arqueológico para alcanzar su objetivo de explicar los conflictos, en la medida en que muchos de los rastros que deja la guerra no se preservan. Por esta razón, el autor aboga por una arqueología de los objetos no hallados, pues recaer única y exclusivamente en los remanentes materiales podría llevar a los investigadores a pensar en que el pasado fue mucho más pacífico de lo que realmente fue. Vencl (1984: 131, traducido por el autor) afirma que "la investigación de la guerra en arqueología representa un caso particular de investigación sobre un fenómeno histórico que dejó desproporcionadamente pocos restos materiales en contraste con el amplio alcance de sus consecuencias sociales".

Sutherland \& Holst esgrimen la idea de que el conflicto es una de las principales causas de cambio y los campos de batalla son sus escenarios. "Por esta razón, los campos de batalla pueden ser estudiados como sitios de transición política y social, y los eventos que tuvieron lugar en éstos son la esencia de la determinación contemporánea de cambio y estabilidad" (Sutherland \& Holst, 2005: 11, traducido por el autor). Vencl (1984:117) enunció esta idea dos décadas más temprano, al argüir que el conflicto armado es la causa primaria del cambio. Sabick \& Dennis (2011) añadirían que las batallas desempeñan un papel primordial en la definición de las naciones. En síntesis, la mayoría de los arqueólogos que se ocupan del conflicto están de acuerdo en que las guerras son un motor de cambio. Vencl (1984: 119) afirma que esto es cierto desde los albores de la humanidad. Según él, la violencia en sí misma es aún más vieja que la humanidad. e la manera en que el muñeco se inserta en conceptualizaciones sobre ciudad y ciudadanía en La Paz. 


\section{ESTADO DEL ARTE}

Las naves de guerra han sido un foco de estudio de la arqueología subacuática desde sus albores. Un año después de las excavaciones pioneras en el Cabo Gelidonia en 1960, el buque de Guerra Vasa fue recuperado del fondo del Puerto de Estocolmo sin ser desensamblado (Cederlund, 2006). A pesar de la onerosa inversión, los remarcables resultados alcanzados por los suecos estimularon el orgullo británico que llevó a financiar el segundo mayor proyecto en la historia de la arqueología náutica. Las prospecciones en busca del Mary Rose se iniciaron en 1965, y en 1982, como el Vasa, el buque británico fue extraído del fondo del estrecho de Solent (Marsden, 2003). La década de 1970 trajo consigo el interés en los buques metálicos que se mantiene vigente hasta la fecha. Los proyectos de arqueología náutica en pecios de buques de guerra se han multiplicado a nivel mundial en años recientes y ahora comprenden un amplio espectro temporal - la antigüedad (Casson \& Steffy, 1991), el medioevo (Kimura et al., 2013), el mundo moderno (Martin, 1975) y la época industrial (Conlin \& Russell, 2006, 2011; McKinnon \& Carrell, 2016). Hoy en día, además de buques y submarinos, también se estudian otros vestigios de la guerra bajo el agua, predominantemente vehículos como tractores anfibios (Arnold, 2016), tanques de guerra (Hanks, 2016) e incluso, aeronaves (Smith, 2004; Bell, 2016).

El enfoque particularista histórico-cultural temprano recaía casi plenamente en las fuentes documentales y favorecía las investigaciones de los barcos en sí y los artefactos contenidos en los mismos, enfatizando en la artillería (Guilmartin, 1982, 1983; Martin, 1994; Hildred, 2011). Esta perspectiva estuvo atada a las ideas de migración y difusión para la explicación del cambio en el registro arqueológico (Cederlund, 1985). Un tono nacionalista puede percibirse en algunas contribuciones de esta tendencia. Durante la etapa temprana de la arqueología náutica de buques de guerra, se hicieron grandes contribuciones a la conservación de materiales procedentes del medio subacuático, como resultado del hecho de que las excavaciones totales y la recuperación de los pecios eran las prácticas prevalecientes. Además de la recuperación del Vasa y el Mary Rose sin ser desensamblados, se hicieron otros esfuerzos magnánimos para adelantar excavaciones totales, como la construcción de ataguías (cofferdam) para remover el agua circundante o prevenir los efectos indeseados de la corriente y las olas en las excavaciones. Utilizando este método, el bergantín británico Betsy fue excavado en Yorktown, Virginia, en la década de 1980 (Broadwater, 2011: 184).

Lejos de haber sido trascendido, el enfoque histórico particularista sigue siendo empleado hoy. No obstante, los estudios recientes se han inclinado hacia la comprensión de los campos de batalla que, siguiendo los avances de la arqueología del conflicto en tierra (Sutherland \& Holst, 2005; Scott \& McFeaters, 2005), tratan de ir más allá de la forma y función de los barcos y los objetos contenidos en ellos. Esta perspectiva busca reconstruir la progresión de eventos y tácticas utilizadas por las fuerzas que se enfrentaron en combate naval, a partir de los patrones en el registro arqueológico (Colin \& Russell, 2011; Broadwater, 2011; Kimura et al., 2013). Desde este paradigma se aboga por el estudio de las fuentes arqueológicas e históricas como líneas separadas de evidencia. En vez de buscar corroborar los relatos historiográficos, la información arqueológica es empleada para contrastar y revisar lo que dice la documentación escrita (Nasti, 2008; Colin \& Russell, 2011; Elkin et al., 2011; Sabick \& Dennis, 2011).

Bajo la influencia de los programas de Manejo de Recursos Culturales (CRM) y la arqueología de patrones de asentamiento, las prospecciones dejaron de emplearse exclusivamente para localizar los sitios más grades y representativos para excavarlos posteriormente. La información obtenida en las prospecciones 
se volvió importante para el análisis arqueológico por sí misma (Trigger, 1996: 377). Acorde con Richard Gould (2011: 14, traducido por el autor): "Una prospección (...) representa un plan que, si se sigue con el suficiente rigor, proveerá resultados de la entereza de los contenidos arqueológicos del área total o dominio a un nivel de probabilidad predeterminado y aceptable".

La metodología de la arqueología de campos de batalla consiste en el registro detallado y minucioso de patrones espaciales y en la recuperación de las evidencias culturales y medioambientales de procesos de formación de sitio (Colin \& Ruseell, 2006: 41-42). La implementación y el desarrollo de los Sistemas de Información Geográfica (SIG) en arqueología ha sido uno de los mayores aportes del procesualismo. De la mano de estos, los detectores de metales se han convertido en una herramienta muy significativa en el estudio de campos de batalla, aunque rara vez se explotan bajo el agua con el provecho que han sido empleados en tierra. Una excepción parece ser el proyecto Valcour Bay, cuyos investigadores afirman ser los primeros en haber estudiado un campo de batalla sumergido de manera plenamente sistemática (Cohn et al., 2007).

Desde principios de la década de 1990, las limitaciones presupuestales y la creciente preocupación relacionada con la preservación en tierra a largo plazo, han conducido a la disciplina por el camino de las excavaciones parciales y la preservación in situ. No obstante, existen algunos ejemplos recientes de excavación total y recuperación de naves de guerra, como el caso del submarino Hunley en la Bahía de Charleston en el año 2000 (Colin \& Ruseell, 2006).

A partir de ese mismo año, comenzó a desarrollarse un interés postprocesual en las naves de guerra y los campos de batalla. Este puede rastrearse en la publicación más reciente de Fred Hocker (2011) sobre el Vasa, uno de cuyos capítulos se titula "El Barco de Guerra Simbólico". Finalmente, McKinnon (2016), desde la perspectiva del Manejo de Recursos Culturales (CRM por sus siglas en inglés), aborda el tema de la multivocalidad en la interpretación de los campos de batalla, así como la necesidad de tener en cuenta a los depositarios de ese patrimonio. Podría decirse que este enfoque se acompaña de un interés por el proceso hermenéutico, y confiere a los individuos cierto tipo de agencia o capacidad de alterar su destino, en contraposición a las ideas de corte procesual que aluden a comportamientos constreñidos por sistemas.

Más allá del almacenamiento digital y el procesamiento computarizado de la información recabada, las herramientas y métodos de prospección, excavación y recuperación no han cambiado significativamente en las últimas cinco décadas, aunque ahora son mucho más poderosas y precisas. La prospección geofísica, acompañada de la investigación etnográfica e histórica, continúa siendo el medio principal para localizar y prospectar naufragios, materiales aislados y campos de batalla acuáticos.

En su juiciosa revisión de la arqueología de campos de batalla en Latinoamérica, Landa (2013: 271) afirma con razón lo que el presente autor ha podido corroborar:

Llevar adelante la búsqueda bibliográfica relacionada con la producción latinoamericana vinculada al estudio arqueológico de episodios bélicos pretéritos no es tarea sencilla. Este tipo de labor arqueológica relativamente nueva no es conocida entre la mayoría de nuestros colegas (dedicados principalmente a momentos pre-hispánicos), situación que dificultó el rastreo bibliográfico. Otra situación llamativa fue el hecho del desconocimiento mutuo de los arqueólogos latinoamericanos en relación a lo escrito por sus colegas del área. 
En el caso de la arqueología subacuática, el panorama es un poco más alentador, ya que gran parte de los investigadores latinoamericanos se conocen entre sí y han compartido múltiples espacios académicos. No obstante, las investigaciones sobre naves de guerra han sido escasas y algunas de ellas aún no han dado lugar a publicaciones académicas o permanecen en la literatura gris, tal como sucede con varios pecios registrados en aguas mexicanas por la Subdirección de Arqueología Subacuática (SAS) del Instituto Nacional de Antropología e Historia (INAH). La investigación en curso sobre el pecio Cañón de Cañones, identificado como la HMS Meleager, no obstante, dio lugar a la tesis de Guzmán (2017), cuya publicación se está planificando. Numerosas naves de guerra halladas en la península de Yucatán y el naufragio 40 cañones aún aguardan a ser publicados.

En el caso de Uruguay, las investigaciones sobre la fragata española San Salvador, hundida en 1812 en la Bahía de Maldonado, han dado lugar a las publicaciones de Nasti (2001, 2008). Sin embargo, todavía se esperan las publicaciones de las investigaciones arqueológicas en el pecio Agamenón, hundido en 1809 en la misma Bahía, así como las del naufragio del crucero de guerra alemán Graf Spee, echado a pique intencionalmente en 1939. Las publicaciones de Bound (1998b) y Bound \& Bado (1998) incluyen fotografías de objetos recuperados en ambos pecios, pero en términos generales se centran exclusivamente en la información histórica y en un relato anecdótico de la recuperación de artillería en ambos pecios.

La investigación de la nave de guerra británica HMS Swift caída en desgracia en 1970 en Puerto Deseado, Argentina, es ejemplar para los colegas de la región. Entre otras publicaciones, el libro de los investigadores del Programa de Arqueología Subacuática (PROAS) del Instituto Nacional de Antropología y Pensamiento Latinoamericano (Elkin et al., 2011) brilla por sus ilustraciones, su rigor y su compromiso ético en el tratamiento de los restos fúnebres hallados. A la escueta lista de publicaciones latinoamericanas sobre naves de guerra y campos de batalla acuáticos, se suman los trabajos adelantados en Chile por Carabias (2008, 2009) y su equipo sobre la Batalla Naval de Iquique y, específicamente, sobre la corbeta Esmeralda hundida en 1879 (Carabias et al., 2013); las investigaciones en la fragata de guerra británica del siglo XVIII HMS Wager, hundida en la Patagonia occidental; y los trabajos sobre la barca de transporte de la Armada Chilena Infatigable (1855) (Carabias, 2018), sobre los cuales se está preparando un publicación para IJNA que sintetizará los casi 13 años de trabajo.

En el caso colombiano, se cuentan las investigaciones de Del Cairo Hurtado $(2009,2013)$ sobre el paisaje de la guerra en Cartagena de Indias, donde se han localizado tres naufragios relacionados con el asedio británico de 1741. En el caso brasileño, se han adelantado investigaciones en un sitio que comprende los pecios Utrecht y Nossa Senhora do Rosário, hundidos durante una confrontación bélica en 1648 en la Bahía de Todos los Santos (Torres y Castro, 2012, Manders et al., 2016); y los trabajos arqueológicos llevados a cabo en el galeón Santíssimo Sacramento, hundido en 1668 en el Rio Vermelho, que dieron lugar a numerosas publicaciones (Neto, 1977, 1979; Guedes, 1981; Guilmartin, 1982, 1983). Como se señala más arriba, la mayoría de los trabajos latinoamericanos han seguido una senda propia y diferente de las investigaciones anglosajonas. En esta medida, sólo se hará mención de algunos de ellos en lo sucesivo. Las investigaciones de la región ameritan por sí solas una publicación adicional exclusivamente dedicada a ellas. 


\section{HISTORIA Y TEORÍA}

\section{Enfoque particularista histórico-cultural: de las naves, sus contenidos y características}

Aunque los arqueólogos que trabajan desde una perspectiva particularista histórico-cultural rara vez hacen explícita su orientación teórica, la gran mayoría de estudios sobre pecios de embarcaciones de guerra pueden clasificarse como tales por su enfoque descriptivo y confianza en la información provista por las fuentes documentales. La arqueología histórico-cultural trata de definir culturas arqueológicas basándose en conjuntos de rasgos y explica el cambio como el resultado de migraciones o de la difusión (presiones ejercidas desde afuera de la sociedad en estudio). Este enfoque puede estar asociado a tendencias nacionalistas (Trigger, 1996: 211-311).

El paradigma histórico-cultural puede ser claramente ejemplificado con el trabajo temprano del arqueólogo sueco Carl-Olof Cederlund (1985) sobre el Vasa. El autor inicia su artículo caracterizando la construcción naval holandesa durante el siglo XVI y comienzos del siglo XVII; y afirma que, aunque las naves holandesas eran más livianas y tenían una vida útil más breve, también eran significativamente más eficientes que las construidas en otros lugares y eran alrededor de un $40 \%$ menos costosas. El autor señala que, por estas características, la tradición de la construcción naval holandesa llegó a expandirse ampliamente a través de la difusión de embarcaciones vendidas o capturadas en la guerra por otras potencias marítimas. La tradición también fue transferida por constructores navales extranjeros que visitaban Holanda y constructores navales holandeses que viajaban a otras regiones. En tiempos tardíos, la distribución de manuales de construcción naval también desempeñó un papel prominente. Basándose en fuentes documentales, Cederlund explica que el Vasa fue fabricado por los constructores navales holandeses Henrik Hybertsson y Henrik Jacobsson. El autor agrega que como las naves suecas no estaban hechas para navegar en aguas poco profundas como las holandesas, el Vasa no es comparable con las embarcaciones del siglo XVII que navegaban en aguas holandesas, pero sí con aquellas que otras potencias ordenaban construir en Holanda. Partiendo nuevamente de la documentación escrita, el investigador demuestra que el diseño de la nave sueca estuvo fuertemente influenciado por un enorme buque de guerra que estaba siendo construido en los astilleros holandeses con destino a ser utilizado en Francia. Para reforzar sus conclusiones derivadas de las fuentes documentales, Cederlund se ocupa de la cultura material y explica que, de las seis reglas de carpintería encontradas a bordo, algunas estaban divididas en 11 pulgadas y otras en 12, lo que demuestra la utilización simultánea de las unidades de medida suecas y holandesas. La construcción basada en el fondo, utilizando clavijas de madera para mantener las tracas del forro en su lugar antes de la ceremonia de botadura y algunas reparaciones ahorrativas, conocidas como Dutchmen, son piezas clave en su argumento. Aunque el paradigma que subyace a su hipótesis puede parecer anticuado, el argumento de Cederlund ha recibido soporte de evidencias recientes. El espesor y el ancho de la quilla constituye 1/77 de la eslora del buque, lo que coincide con el tratado holandés escrito por Cornelis van Yk en 1697. Otras coincidencias de patrones geométricos y aritméticos en las proporciones de ciertas dimensiones pueden vislumbrarse cuando se compara el buque con el tratado del holandés Witsen (1671), como el hecho de que el fondo representa 2/3 de la manga total (Rose, 2014). 
En el caso de la arqueología subacuática latinoamericana, las influencias de este paradigma pueden percibirse en los trabajos adelantados en la HMS Swift. Aunque la labor efectuada no podría clasificarse como particularismo histórico, a la luz de un juicioso estudio de fuentes documentales constatado por el registro arqueológico, los investigadores de la corbeta de guerra ponen de manifiesto que los constructores navales británicos del siglo XVIII fueron fuertemente influenciados por los franceses, quienes recientemente habían descubierto y aplicado con éxito la teoría del metacentro. Los autores profundizan en la influencia francesa al demostrar que la Swift y su buque hermano Vulture, estaban basados en la corbeta Epreuve, capturada a los franceses en 1760. Por las razones expresadas, la Swift presenta marcadas diferencias con las demás corbetas británicas de su época y, en cambio, exhibe notorias similitudes con la tradición francesa. Sin embargo, la reducción de la manga de la nave en su cubierta superior con respecto a su punto de manga máxima (tumblehome), que solía ser muy pronunciada en las naves francesas, fue efectuada para ajustarse mejor al estilo de los diseños británicos (Elkin et al., 2011: 100-109).

Como autor de un popular manual de arqueología marítima y profesor de la Universidad de St. Andrews en Escocia (uno de los primeros programas de arqueología marítima), Colin Martin ha hecho contribuciones significativas y su legado histórico-particularista está ampliamente extendido en el medio. Las investigaciones de Martin $(1975,1994)$ sobre los pecios de la Armada Española de 1588 representan un segundo ejemplo del enfoque histórico-cultural, pues enfatizan en la descripción minuciosa de las naves y sus contenidos, con una fuerte influencia de la documentación escrita disponible.

En el trabajo de Martin (1994) que se ocupa de las armas incendiarias halladas en la Trinidad Valencera, un buque de la Armada Española de 1588, se vislumbra la tendencia particularista en las descripciones detalladas de las armas empleadas en el combate de cercanía y el abordaje.

Se deduce de la siguiente frase que su metodología privilegia las fuentes documentales como línea principal de evidencia y que los hallazgos arqueológicos son empleados para corroborar lo que en estas se dice: "Las fuentes documentales que relacionan el equipamiento de la flota mencionan dos tipos de armas, alcancías y bombardas. Estas pueden ser identificadas, respectivamente, como ollas de fuego rellenas de pólvora y tubos de madera mediante los cuales se descargaban fuegos ofensivos en series" (Martin, 1994: 207, traducido por el autor). A lo largo del artículo, se describe la forma y se explica la función de las alcancías alquitranadas y las bombas. Los hallazgos son comparados con otros similares y equivalentes encontrados en otros naufragios y en la iconografía; e incluso, es traída a colación la receta para crear la pólvora contenida en ambas armas incendiarias.

Martin (1975: 11) parece dar soporte al mito de la derrota de la "magnificente y poderosa" Armada Española, dando así continuidad al clamor nacionalista británico con respecto al suceso en que se engrandece la flota peninsular para encumbrar los pretendidos logros de la potencia insular. Esto puede deducirse de frases tales como "Un repentino cambio en los vientos providencialmente salvó a la Armada de los bancos de arena, pero no de la flota británica” (Martin, 1975: 18, traducido por el autor). No obstante, el autor reconoce que, aunque los británicos les inflingieron algún daño a las naves hispanas, sólo una de ellas naufragó como resultado del fuego enemigo. El resto de las pérdidas se produjo como efecto de las condiciones climáticas en las costas escocesas e irlandesas. El mito de la derrota de la Armada Española ha sido ampliamente discutido por los académicos españoles (Casado-Soto, 1988, Alcalá-Zamora, 2004), pero aún sigue siendo muy extendido entre los investigadores angloparlantes. Broadwater (2011: 177, traducido por el autor), aunque más ecuánime, sigue considerándola una derrota: “...la Armada fue derrotada por una 
combinación fortuita de buques de guerra ingleses y severas tormentas que dispersaron e hicieron naufragar muchas naves españolas".

Pese a su inclinación inicial por el particularismo y la descripción de hallazgos específicos procedentes de naufragios, Martin adquirió una perspectiva más holística de las metas de la arqueología en sus trabajos más recientes y, en esa medida, puede ser situado en la transición entre paradigmas. Sin escatimar en su riguroso interés por las tipologías y la seriación, en sus trabajos más recientes, Martin (2001: 383) propende por la “desparticularización de lo particular” en un estudio complementario de la artillería, la cerámica y los remanentes de embarcaciones. El apartado sobre cerámica aún retiene un enfoque clasificatorio y descriptivo, pero al referirse a la artillería rebasa las categorías de forma, función, proveniencia y datación, y ofrece una explicación sobre el "precario desempeño de la artillería de la Armada" (Martin, 2001: 388, traducido por el autor). Más allá de reafirmar su adherencia al clamor nacionalista británico más de cuarenta años después de sus contribuciones pioneras, Martin busca explicaciones e, incluso, emplea la arqueología experimental para sustentar el desempeño superior de las cureñas de cuatro ruedas empleadas por los británicos, con respecto a las de dos ruedas empleadas por los españoles. Su analogía experimental intercepta el enfoque procesual. Al comparar las armas en las naves de la Armada Española, explica que más de doscientos años antes de la Revolución Industrial, los fabricantes de armas, aunque carecían de conocimientos matemáticos avanzados, se anticipaban al rumbo de los estándares repetibles. En este punto, se cuestiona sobre sobre el sistema socioeconómico en que los barcos se produjeron y en que estuvieron embebidos.

Los comentarios de Martin acerca del casco de la Dartmouth, fragata inglesa de guerra de finales del siglo XVII, muestran una perspectiva mucho más crítica frente a la documentación histórica, y reconocen un potencial mucho mayor en los vestigios arqueológicos como fuente para refinar las narrativas basadas en documentos histórica y revelar historias de comunidades que no están representadas en los registros escritos. Martin clarifica que los tratados de construcción naval, comúnmente tomados como fuentes definitivas en las reconstrucciones llevadas a cabo por los arqueólogos náuticos, fueron escritos por intelectuales distantes de los astilleros en que los constructores navales iletrados construían las naves reales. Resultado de lo anterior, sostiene que los pecios son la única fuente confiable sobre las naves verdaderas y las prácticas constructivas (Martin, 2001: 395-396). El autor deja entrever algunos visos de arqueología de campos de batalla y una tendencia al procesualismo al escribir:

La arqueología y la investigación documental han desempeñado un papel muy importante en el avance de la interpretación del conflicto de la Armada, una disciplina complementando e iluminando a la otra. Esto ha hecho posible no solamente las referencias a aspectos particulares de la campaña como parte de una narrativa histórica descriptiva, sino también, por asociación e implicación, a la identificación de algunas dinámicas culturales y tecnológicas más amplias que condicionaron los eventos dentro del contexto de su mundo contemporáneo (Martin, 2001: 389, traducido por el autor).

Una de las contribuciones más influyentes en la arqueología subacuática en general y en la arqueología de buques de guerra y batallas navales en particular, es la obra del profesor emérito estadounidense de la Universidad de Brown, Richard Gould, Arqueología e Historia Social de los Barcos. La obra, originalmente publicada en el 2000, fue reeditada en el 2011 para incorporar las contribuciones de aquella década. Debe aclararse que Gould reconoce en Martin una fuerte influencia y retomándole anota que los elementos de 
sujeción férreos podían usufructuarse de manera más rápida y sencilla que los de madera, permitiendo emplear mano de obra no calificada en la construcción de las naves. No obstante, la vulnerabilidad de los elementos de sujeción de hierro ante la corrosión hacía que su vida útil fuese breve. Por las razones anteriores, los elementos de sujeción ferrosos representan ese tránsito a la producción en masa de mercantes en la Venecia del siglo XVI, durante un período en que este centro de producción experimentaba un proceso de declive por las presiones de la competencia (Gould, 2011: 7). Acorde con Gould (2011: 4, traducido por el autor): "La complementariedad de la generalización científica social y el particularismo histórico tiene el potencial de mover la arqueología subacuática hacia ideas más creíbles sobre lo que acaeció en el pasado de la humanidad". Lo anterior resalta el gran legado de Martin.

En mi opinión, el particularismo histórico hizo y sigue haciendo aportes innegables a la arqueología de los buques de guerra, en la medida en que dentro de sus principales premisas se encuentra la exhortación a efectuar descripciones muy detalladas y clasificaciones del registro arqueológico. Todos los arqueólogos responsables coincidirían en señalar que dichas actividades forman parte de cualquier trabajo riguroso de registro. No obstante, la etapa descriptiva debe trascenderse. Es necesario proveer explicaciones de la cultura material y sus relaciones con las dinámicas humanas de cambio y continuidad.

Asimismo, considero que en su anhelo por revelar la etnicidad a través de la clasificación por culturas arqueologías basadas en rasgos comunes, el particularismo contribuyó ampliamente a la elaboración de cronologías y seriaciones que son herramientas indispensables en el trabajo de los arqueólogos. No obstante, la posibilidad de definir etnicidades a partir de la cultura material resulta dudosa; y lo que es aún más delicado, es el tono nacionalista que con frecuencia puede percibirse en los trabajos efectuados. Las narrativas nacionalistas actúan en menoscabo de las minorías y de ciertos grupos sociales al margen del proyecto nacional. La arqueología debe rechazar cualquier tipo de narrativa nacionalista homogenizante; por el contrario, forma parte de su papel el poner de manifiesto la diversidad y visibilizar a las minorías y grupos sociales, cuyo legado escrito es nulo, escaso o mediado por terceros. Tal propósito justifica poner al descubierto su cultura material.

Finalmente, creo que es cierto que las fuerzas de migración y difusión ejercen una influencia grande en el devenir de las sociedades y, por ende, en el desarrollo de su cultura material. Sin embargo, el particularismo histórico-cultural suele pasar por alto que los objetos producidos por una sociedad y la sociedad en sí misma, también pueden cambiar como resultado de fuerzas internas. El papel que desempeña el medio ambiente y los procesos sociales, políticos, económicos y simbólicos de adaptación al mismo, son fundamentales para la compresión del cambio.

\section{Enfoques procesuales: De la tierra al agua, arqueología de campos de batalla}

La aplicación del concepto de sistema en la arqueología procesual estuvo fuertemente influenciada por la Teoría General de Sistemas originada en el campo de la biología. Los trabajos de Binford (1965) y, en especial los de su discípulo Flannery (1968), ejercieron una influencia enorme en la corriente de pensamiento que sostiene que en el registro arqueológico pueden observarse patrones de distribución, derivados de la interacción entre los elementos que componen un sistema. A su vez, cada sistema interactúa con otros y todos ellos están constreñidos por el medio ambiente en el cual tienen lugar. Dado el hecho de que existe interdependencia entre los elementos de un sistema, puede esperarse que la modificación de cualquiera de 
estos componentes origine cambios en los demás y, por ende, en los sistemas relacionados. Esta interdependencia entre componentes, observada a la luz del medio ambiente en que se desarrolla, hace que puedan esclarecerse comportamientos, muchas veces explicables en términos adaptativos.

Otra característica muy importante del procesualismo es su demanda de un estatus científico para la arqueología, cuyo reflejo más evidente consiste en la formulación y comprobación de hipótesis que suelen partir de los patrones de distribución. Estos reflejan comportamientos humanos en tiempos pasados y son la base para establecer generalizaciones.

Acorde con Trigger (1996: 473), el enfoque humanista temprano que estudia el paisaje y la forma en que constriñe las actividades de las personas que en él habitan y hacen uso de él, es la versión postprocesual de los estudios de patrones de asentamiento en la arqueología procesual. La arqueología de campos de batalla tiene un componente paisajístico importante que invita a trascender embarcaciones particulares para considerar un rango más amplio de sitios relacionados con el desarrollo de la batalla, algunos de los cuales pueden no estar directamente imbuídos en el campo de fuego. Según la caracterización de Trigger, la arqueología de campos de batalla podría clasificarse como postprocesual, contextual y del paisaje, pero aun considerando conceptos tales como "movimientos individuales" e "iniciativa" que podrían asociarse con la agencia, el vocabulario más empleado en la arqueología de campos de batalla frecuentemente incluye conceptos como "patrones", “comportamiento" y "sistema”, categorías de análisis que lo acercan más a la perspectiva procesual. De una u otra forma, es difícil situar la arqueología de campos de batalla dentro de una u otra tradición. Ésta se encuentra teóricamente orientada por el análisis militar del terreno. Más allá de las naves y sus contenidos, tiene por objeto de estudio el proceso de la batalla y considera las fuentes arqueológicas e históricas como líneas separadas de evidencia. Asimismo, enfatiza en la importancia de los procesos de formación de sitio, introducidos a la arqueología terrestre por la obra de Schiffer (1987) y a la arqueología marítima por la obra de Muckelroy (1978). El primer autor, notorio por contribuciones al procesualismo tan célebres como las de Binford o Flannery, también hizo grandes aportes al desarrollo del concepto de comportamiento en la arqueología (Schiffer, 1976; 2010; 2011).

Algunas guías muy influyentes sobre la teoría y los métodos de la arqueología de campos de batalla han sido publicadas en los países británicos y en los Estados Unidos (Sutherland \& Holst, 2005; Scott \& McFeaters, 2011). Aunque predominan los estudios de arqueología terrestre, algunos de estos textos deben ser considerados al aproximarse a los ejemplos subacuáticos en aras de comprender los principios básicos que los estudios arqueológicos subacuáticos recientes afirman aplicar.

Acorde con Trigger, la arqueología procesual vio el hecho de privilegiar las fuentes históricas como anatema de la ciencia arqueológica (Trigger, 1996: 499). Sutherland \& Holst reafirman la idea hoy popular de los arqueólogos históricos de que las fuentes escritas y arqueológicas deben ser tratadas como líneas de evidencia separadas, en la medida en que las fuentes escritas frecuentemente están basadas en relatos personales y los individuos enfrentados en batalla normalmente no están en una posición que les permita considerar la totalidad del campo. Adicionalmente, están constreñidos por el ambiente traumático de la confrontación y, por esta razón, este registro debe ser visto como sesgado y poco confiable (Sutherland \& Holst, 2005: 3). 
Sabick \& Dennis (2011) coinciden en que el registro arqueológico debe ser tratado como una fuente de evidencia independiente de la documentación escrita. Scott \& McFeaters (2011), en alguna medida, comparten esta opinión, aunque lo expresan en términos menos radicales:

La importancia del registro arqueológico o físico no es su riqueza, sino que es una línea de evidencia independiente que cuenta una historia diferente o incrementa el registro documental y la tradición oral... Esta línea de evidencia independiente puede ser recuperada, registrada e interpretada. Su poder real reside en que puede ser usada para correlatar, corroborar, o contrastar las fuentes documentales o los testimonios orales para determinar lo que mejor se ajusta o qué tan acertadas son varias fuentes de información (Scott \& McFeaters, 2011: 121, traducido por el autor).

En dirección similar, Broadwater (2011:77, traducido por el autor) comenta que los datos arqueológicos “...pueden agregar una perspectiva completamente nueva al registro escrito de los eventos militares en el mar".

Gould enaltece el valor de los estudios pioneros de arqueología subacuática histórica, pues, aunque aún abundan los detractores de la arqueología en períodos para los cuales existen fuentes escritas, personajes como Martin hicieron grandes avances rumbo a la aceptación de la arqueología subacuática de épocas recientes en la comunidad académica. Para Gould quienes ponen en duda la relevancia de la arqueología en períodos para los cuales se tienen evidencias escriturales, niegan categóricamente el registro arqueológico como fuente primaria y legítima de información sobre los comportamientos humanos en el pasado que algunos han denominado histórico (Gould, 2011: 10).

Aunque quizás tampoco pueda clasificarse como un trabajo de corte netamente procesual, un elemento que indudablemente contradiría la inclusión del grupo de investigadores que adelantaron la excavación parcial de la HMS Swift en el paradigma histórico cultural, es su trabajo crítico al contrastar las fuentes documentales con el registro arqueológico (Elkin et al. 2011: 50-51). A través de su obra, son varios los ejemplos con que los autores demuestran que en muchas oportunidades el registro arqueológico no coincide con lo que se esperaría de un análisis basado exclusivamente en las fuentes. El equipo demuestra que la extensión del codaste y el alcázar, la localización de la cocina y la introducción del palo de mesana difieren de lo hallado en la evidencia documental. Asimismo, el registro arqueológico revela una disyuntiva con la documentación escrita en la disponibilidad de granos de mostaza, no obstante la negativa del almirantazgo a proveer este alimento, según quedó plasmado en los textos de la época.

Sabick \& Dennis (2011), al expresar su desconfianza en los relatos históricos y el "conocimiento popular" de las batallas, anotan que la arqueología puede convertirse en una valiosa herramienta para contradecir los discursos que sobrevaloran la gloria de las batallas y abren la puerta a que sean empleadas como propaganda para persuadir al público a tomar parte de conflictos sucesivos. Coherente y preocupantemente Bock's Car, el B-29 que arrojó la bomba atómica sobre Nagasaki está desplegado en el museo de la fuerza aérea estadounidense. Acorde con el arqueólogo norteamericano Delgado (1991: 145, traducido por el autor), este avión demuestra "el orgullo estadounidense en sus grandes y terribles logros, así como un impactante ejemplo material del poder y la riqueza estadounidense”, mientras que el la Cúpula Genbaku o Domo de la Bomba Atómica en Japón rememora la vulnerabilidad humana. Aquí cabría preguntarse si un vehículo de guerra que causó semejante daño, es digno de ser desplegado en un museo; en especial, si aquello que su exposición promueve es orgullo por un gran logro. En consideración del presente 
autor, todo depende del tratamiento museográfico, pero éste dista de ser el sentimiento que debe promoverse. Independientemente de si se trata de una gran proeza tecnológica, ninguna acción que haya conllevado la pérdida de vidas inocentes debe ser celebrada como un gran logro.

El arqueólogo estadounidense Douglas Scott, citado más arriba, es reconocido mundialmente como uno de los a padres de la arqueología de campos de batalla, principalmente a raíz de sus sobresalientes contribuciones en el estudio de la Batalla de Little Bighorn (1987, 1989, 1998). En una entrevista sostenida en el año 2005 con la revista Archaeology del Archaeological Institute of America, Douglas sostiene:

\begin{abstract}
Como cualquier otro estudio arqueológico del pasado, el estudio de los campos de batalla tiene múltiples fines. Uno es iconográfico o enfocado en la investigación de sitio. En la mayoría de los trabajos sobre campos de batalla, uno de los objetivos consiste en hallar patrones de artefactos relacionados con la batalla que sirvan para un análisis, cuyos resultados permitan comprender los detalles de la batalla con mayor precisión. (...) Más allá del valor de la interpretación de sitios específicos de una batalla, el campo de la arqueología de campos de batalla es capaz de buscar respuestas a cuestiones más amplias - patrones de combate, si se quiere, en el tiempo y en el espacio. Estos patrones nos ayudan a comprender la forma en que los combatientes utilizaron el terreno, desarrollaron tácticas, ejercieron el comando y el control; a identificar la desintegración táctica que puede resultar de la derrota, a apreciar el efecto de la perplejidad de la guerra, y, en general, a alcanzar una apreciación más amplia de la antropología de la guerra (Scott, 2005, traducido por el autor).
\end{abstract}

En un artículo reciente, McFeaters se sumó a Scott para sintetizar la "Historia y los Desarrollos Teóricos en la Arqueología del Conflicto" (Scott \& McFeaters, 2011). La perspectiva procesual de los autores puede deducirse fácilmente de su vocabulario cuando afirman que "los patrones culturales, las actividades humanas, y los comportamientos asociados con el conflicto" (Scott \& McFeaters, 2011: 104: 4-7, traducido por el autor) pueden ser recuperados de los escenarios de conflicto empleando las teorías y métodos arqueológicos apropiados.

Scott \& McFeaters consideran que el breve período de tiempo del cual se ocupa la arqueología de campos de batalla, más que un obstáculo o impedimento, se erige en oportunidad para examinar acciones individuales, modeladas por la tecnología bélica y el contexto sociocultural de los combatientes. Desafortunadamente, la posibilidad de rastrear movimientos individuales aplica solamente a los campos de batalla terrestres modernos. Los métodos disponibles para el trabajo subacuático hasta ahora han demostrado ser incapaces de un grado de detalle semejante.

Scott fue probablemente uno de los primeros académicos en promover la utilización de teorías y métodos militares para la interpretación del registro arqueológico. Algunos de los principios militares pueden resumirse de la siguiente manera: "La estrategia refiere al desarrollo de ideas para usar el poder para alcanzar objetivos. El nivel operacional es donde la política estratégica se organiza para una acción específica” (Scott \& McFeaters, 2011: 113, traducido por el autor). Todas las acciones que respaldan una misión militar son "operaciones" y una serie de operaciones interrelacionadas que buscan un objetivo estratégico y operacional dentro de un marco espacio-temporal constituyen una campaña. "La utilización de la fuerza en el combate es la táctica, la esfera del combate cercano o directo. Este nivel de operación se ocupa de cómo las fuerzas en oposición emplean los recursos, la información y los lugares disponibles para derrotar o destruir a sus enemigos" (Scott \& McFeaters, 2011: 113-14, traducido por el autor). El concepto de operación es el 
correlato de las ideas y las acciones específicas (comportamientos) que pueden ser rastreadas en el tiempo y en el espacio a través de la observación del registro arqueológico.

A pesar de que ciertas áreas no son parte del campo de batalla como tal, en cualquier intento serio de comprender el desarrollo de una confrontación, es crucial considerarlas:

Espacialmente, (la batalla) incluye áreas de operación, el área inmediata ocupada por una fuerza de combate de la que es responsable el comandante. En torno a este espacio está el área de influencia, la zona sobre la que un comandante puede influir directamente en una maniobra de fuego. Más lejos está el área de interés, que es relevante para la misión del comandante aunque sea controlada por fuerzas enemigas (Scott \& McFeaters, 2011: 114, traducido por el autor).

En la batalla también están involucradas instalaciones e infraestructura que deben considerarse si se pretende una aproximación arqueológica al conflicto. Algunas de estas instalaciones están fuera de la zona de fuego, como las estaciones y bases permanentes desde las cuales se movilizan las fuerzas. Por otra parte, cuando las fuerzas están desplegadas, comúnmente erigen bases temporales o de proyección en el área de operaciones. Éstas suplen la ausencia de las bases permanentes (Scott \& McFeaters, 2011: 114). Las áreas e instalaciones frecuentemente dejan huellas en el registro arqueológico.

Scott y McFeaters ofrecen una definición concisa del método militar de análisis del terreno KOCOA, que es supremamente útil y se ha hecho muy popular entre los arqueólogos que se ocupan del conflicto en Estados Unidos:

La sigla KOCOA, viene del inglés, terreno clave, observación y campos de fuego, encubrimiento y ocultamiento, obstáculos y rutas de aproximación. En el lenguaje militar terreno clave es una localidad o área que ofrece una ventaja marcada al grupo combatiente que la controla. La observación es definida porque puede verse desde un lugar o rasgo determinado de paisaje, en esencia cuenca visual. Encubrimiento y ocultamiento es cobertizo o protección de la observación y el fuego enemigo. Los obstáculos son cualquier rasgo natural o antrópico que previene, retrasa, o desvía el movimiento de fuerzas militares. Las rutas o avenidas de aproximación son rasgos naturales o antrópicos que permiten a las fuerzas atacantes alcanzar a una fuerza enemiga (Scott \& McFeaters, 2011: 114, traducido por el autor).

La única guía escrita específicamente para campos de batalla acuáticos fue publicada en 2011 por Sabick \& Dennis. Como sus compatriotas estadounidenses Collin \& Russel (2011), Sabick \& Dennis exhortan a los lectores a poner mucha atención en los procesos de formación de sitio, que también fueron una de las principales líneas de investigación en los trabajos adelantados en el sitio de la HMS Swift en Argentina (Elkin et al. 2011: 321-351; Grosso, 2014) y en los pecios Utrecht y Nossa Senhora do Rosário en Brasil (Torres \& Castro, 2012). Citando a Fox (1997), otro estadounidense que trabajó junto a Scott en la investigación arqueológica de la Batalla de Little Bighorn, los autores explican la propuesta teórica de estabilidad/desintegración en los siguientes términos que están claramente asociados al paradigma procesual binfordiano:

El éxito en la modelación en el discernimiento de comportamientos de combate es, en alguna medida, dependiente de la proposición de que no existen dos conjuntos de acciones distintivas y diferentes responsables del mismo patrón arqueológico. Aunque las tácticas y la tecnología han cambiado dramáticamente a través de los siglos, el comportamiento en la guerra ha permanecido marcadamente predecible en modos fundamentales. O bien los hombres pelean o no lo hacen. Cuando los ejércitos 
pelean sus acciones son predecibles. Las tácticas gobiernan el comportamiento. El deseo de pelear, promovido por el liderazgo, sostiene a los hombres en la batalla. Cuando este deseo se pierde, la unidad se desintegra, y la derrota se impone invariablemente. El comportamiento resultante del colapso también es predecible. Moldeado por esta dicotomía, entonces, el combate puede ser modelado con base en la estabilidad táctica y en la desintegración táctica, o estabilidad/desintegración. Ciertas expectativas de comportamiento coinciden con cada una de estas condiciones en la guerra. El registro arqueológico debería reflejar estas condiciones (Fox, 1997: 39-40, citado en: Sabick \& Dennis, 2011: 12, traducido por el autor).

Sabick \& Dennis también resumen el análisis KOCOA, aunque reconocen que las unidades navales no se comportan como las unidades de tierra. En concordancia, explican que el terreno clave puede comprenderse mejor como el estar en una posición favorable con respecto al viento (weather gauge) o ir a favor de la corriente en un río. Esto podría complementarse con las palabras de Gould, quien explica que en los tiempos de la vela:

Los palos y la jarcia interferían con el radio de tiro de la artillería y era difícil situar armas en la cubierta superior pues no podían girarse y dispararse libremente en cualquier dirección. Por esa razón, las baterías principales estaban constituidas por hileras en las bandas del buque y disparaban a través de las portañolas. Esta disposición estuvo en uso por lo menos hasta el siglo XVI, lo que significaba que las armas individuales estaban limitadas en su habilidad de elevarse y moverse transversalmente, tal y como lo evidencian barcos como el Mary Rose. La posición relativa de la propia nave con respecto a la del oponente era más importante a la hora de abrir fuego que la pretensión de precisión del arma (Gould, 2000: 281, traducido por el autor).

Sabick \& Dennis también ofrecen algunos ejemplos de cómo podrían extrapolarse algunos de los conceptos de KOCOA que se aplican en tierra a un contexto acuático y dejan en claro que otros sencillamente no son aplicables. Al utilizar KOCOA como método, es altamente deseable emplear un sistema de información geográfica (SIG) como herramienta principal. Cómo teoría, KOCOA sostiene que el desarrollo del conflicto está determinado por el medio ambiente (paisaje) y es uno de los ejemplos más claros de una perspectiva procesual en el estudio de campos de batalla.

Siguiendo la senda de los textos citados más arriba, Colin \& Russell (2011) y Broadwater (2011) proponen una arqueología de campos de batalla subacuáticos que exhorta a los investigadores a ver más allá de los sitios individuales y las áreas de actividad de pequeña escala, e invita a concentrarse en el paisaje cultural. Los autores instan a considerar la totalidad del contexto de la batalla que comprende una serie predecible de etapas en el comportamiento humano durante un período breve de tiempo, mientras que involucra un área significativamente mayor que el sitio de un naufragio individual. La teoría de rango medio que vincula el registro arqueológico a las interpretaciones de los campos de batalla:

... se basa en la premisa de que la guerra es “...una de las formas más organizadas, premeditadas, y sujeta a patrones del comportamiento humano... las acciones de unidades militares en un campo de batalla están basadas en las tácticas procedentes de la sabiduría militar prevaleciente en cada momento; no son aleatorias. Por esta razón, uno no debería esperar que los restos de batalla estén distribuidos aleatoriamente sobre el campo de batalla. Las tácticas empleadas en el campo de batalla dejan rastros en el registro arqueológico. Subsecuentemente, si las fuerzas naturales y las actividades humanas no han disturbado, mezclado o enmascarado el todo o las partes del campo de batalla significativamente, debería ser posible identificar y definir patrones de artefactos creados por las posiciones y movimientos 
tácticos de unidades militares individuales" (Geier \& Potter, 2000: 13, citado en: Colin \& Russell, 2011: 40, traducido por el autor).

Aunque por tratarse de un trabajo preliminar, Torres \& Castro (2012: 21) no ahondan en la manera en que los sitios deben ser abordados, sí afirman que en futuros trabajos los restos del Utrecht y el Nossa Senhora do Rosário deben ser estudiados conjuntamente, pues forman parte de una sola unidad analítica resultante del enfrentamiento entre las flotas portuguesa y holandesa en Itapirca, Brasil en 1648.

En su artículo sobre la batalla de Yorktown, el arqueólogo estadounidense John Broadwater (2011) exhorta a estudiar los sitios terrestres como parte del paisaje cultural de las batallas acuáticas y sostiene que los estudios arqueológicos de campos de batalla deben ser multidisciplinarios (Broadwater, 2011: 180). El autor afirma que el ambiente físico debe ser cuidadosamente analizado, en la medida en que éste moldea las decisiones y movimientos de guerra. Broadwater ejemplifica esta situación con el hecho de que Yorktown fue elegido por Cornwallis como su base de operaciones, porque era el único puerto que se ceñía a los criterios geo-ambientales de los británicos (Broadwater, 2011: 185).

Desafortunadamente, las tentativas de elucidar las tácticas y la progresión de los ataques en las investigaciones de Broadwater (2011) y Colin \& Russell (2011) dependen en gran medida de las fuentes escritas, y la propuesta de aproximación desde la arqueología de campos de batalla se disuelve en el estudio particularista de embarcaciones separadas, vinculadas únicamente por la documentación escrita.

Los académicos latinoamericanos tampoco han sido ajenos al estudio de los paisajes relacionados con hundimientos de naves de guerra. En su investigación para localizar los restos de la fragata inglesa HMS Wager, el arqueólogo chileno Diego Carabias (2009:3) y su equipo de trabajo, además de considerar varias líneas de evidencia que incluyen la etnohistoria y la etnografía, se propusieron comprender los procesos de construcción y transformación del paisaje cultural de la Patagonia Occidental en el siglo XVIII. Asimismo, el arqueólogo colombiano Carlos del Cairo ha adelantado numerosas investigaciones sobre arqueología del paisaje de la guerra en la Bahía de Cartagena de Indias (2009, 2013). Sus investigaciones, aunque más cercanas a la perspectiva postprocesual, están orientadas por la Teoría de Actores y Redes, desarrollada en la sociología. Sus intereses abarcan territorios costeros y marítimos, cuyas fronteras se diluyen para generar la hibridación del espacio bélico que, además de naufragios y fuertes, comprende también el entorno natural. La influencia del concepto de sistema en el trabajo de Del Cairo (2013:191) puede vislumbrarse cuando se refiere a la configuración de los mapas y el territorio como “...un universo de componentes relacionados de forma interdependiente". El legado procesual en Latinoamérica es también claramente visible en la obra de Nasti (2008: 155) sobre el naufragio de la fragata San Salvador en Uruguay. El autor afirma que su trabajo consiste en “... explicar el patrón espacial que dejan los objetos materiales como consecuencia de ciertos aspectos de la conducta humana. A partir de estos análisis, se construyen modelos que a manera de hipótesis explican la variación de las adaptaciones culturales en determinado espacio y lugar a lo largo del tiempo".

Para concluir este apartado, se hará mención a la reclamación del estatus científico por parte de los arqueólogos procesuales. Gould es quien sostiene este estandarte con mayor firmeza. La siguiente cita sintetiza estas proclamaciones con elocuencia y claridad:

El uso controlado de la evidencia arqueológica acorde con estándares científicos aceptables ha sido siempre el sello distintivo de la buena ciencia arqueológica. Los arqueólogos subacuáticos ahora requieren hacer mayor uso de la arqueológica científica para construir ideas creíbles y generalizables 
sobre cómo se comportaban las gentes de las culturas humanas pretéritas en relación con sus ambientes marítimos. Por ejemplo, las hipótesis derivadas de los estudios meticulosos sobre las prácticas contemporáneas de las navieras pueden ser sometidas a comprobación contra la evidencia física de naufragios antiguos para proveer un panorama de aquello que sucedió y que va más allá de las circunstancias inmediatas del evento, para conectar las condiciones socioeconómicas que lo rodearon (Gould, 2011: 4, traducido por el autor).

En mi opinión, las categorías de patrón, comportamiento y sistema de componentes interdependientes fueron aportes capitales de la arqueología procesual. En el caso específico de la arqueología de la guerra en períodos posteriores al contacto, estos conceptos son de enorme utilidad para el análisis del registro material. La interdependencia muchas veces ayuda a deducir el funcionamiento de elementos que no han dejado un legado físico, pues su comportamiento puede ser elucidado a la luz de sus relaciones con los vestigios disponibles. Las confrontaciones bélicas son actividades que implican un alto grado de organización y habitualmente se rigen por normas previamente establecidas. Las acciones ofensivas y defensivas están íntimamente vinculadas, dependen la una de la otra, y suelen responder a tácticas que dejan huella en el paisaje. La compresión de estrategias y tácticas que orientan comportamientos específicos es uno de los potenciales resultados del análisis de patrones de distribución de vestigios de la guerra. Otro gran aporte de numerosos estudios de la arqueología histórica de corte procesual ha sido su demostración de que las fuentes arqueológicas e históricas deben ser tratadas como líneas de evidencia separadas, pero complementarias, sin dejar de atender a la posibilidad de que el registro material contradiga lo que se afirma en las fuentes.

La formulación de leyes, sin embargo, es una tarea supremamente compleja, pues para que las mismas tengan una aplicación general, deben ser vagas y en ese sentido terminan aportando poco a la compresión de un fenómeno. Si se pretende por el contrario alcanzar un mayor grado de especificidad, las excepciones suelen ser muchas y la ley pierde su potencial explicativo. En su anhelo por hacer de la arqueología una ciencia objetiva, quienes investigan desde esta perspectiva suelen pasar por alto el hecho de que los arqueólogos estamos inmersos en un marco institucional usualmente hegemónico. Los museos, universidades y el común de las entidades para las cuales trabajamos son instituciones de poder, y es desde esta perspectiva que las sociedades objeto de estudio son representadas en narrativas textuales y materiales. Sin duda es inapropiado asumir que los arqueólogos tenemos el monopolio en la interpretación de la cultura material. (Rivolta et al., 2014:17).

\section{La arqueología postprocesual de los vehículos de guerra acuáticos: simbolismo, multivocalidad y hermenéutica}

Algunas de las ideas diferentes que convergen en la arqueología postprocesual pueden deducirse de los trabajos más recientes sobre la arqueología de los buques de guerra. La primera de estas consiste en la preocupación por aspectos tales como el simbolismo. Desde una perspectiva postprocesual, se asume que la arqueología no es una ciencia destinada a la formulación de hipótesis que se someten a comprobación para la formulación de leyes objetivas. Por el contrario, se asume que es una práctica interpretativa que tiene por objeto la búsqueda de sentidos y significados (Johnsen \& Olsen, 1992: 419-420). Los objetos materiales son considerados como irreductiblemente polisémicos; es decir, que pueden significar cosas diferentes para personas distintas, o incluso para una misma persona en diversos momentos (Trigger, 1996: 468). 
Esta idea es fundamental cuando nos acercamos a los vestigios derivados de confrontaciones bélicas y, por esta razón, desde el postprocesualismo se aboga por la multivocalidad en la interpretación del pasado; las diversas voces merecen la misma atención y ninguna de ellas puede erigirse como interpretación única y verdadera. La multivocalidad en la arqueología es, en buena medida, una consecuencia de los movimientos sociales de las minorías por el reconocimiento de sus derechos. Así pues, cuestiona la autoridad institucional de los arqueólogos y busca reconfigurar las relaciones de poder entre los investigadores y los grupos locales, marginales y subalternos, para que ellas se tornen menos asimétricas. Muchos trabajos buscan el empoderamiento de las comunidades a través de la incorporación de sus propias interpretaciones del patrimonio cultural y su participación en la administración del mismo (Hodder, 2008: 198). Esto “equivaldría, por lo tanto, a descentralizar las políticas de representación y gestión del patrimonio arqueológico" (Rivolta et al., 2014: 17).

Atendiendo a lo anterior, la arqueología postprocesual enfatiza en la hermenéutica y las dificultades inherentes al proceso de reconstruir el pasado, en la medida en que el investigador está inmerso en su propio contexto, alejado del pasado que trata de reconstruir (Trigger, 1996: 444 -478). Acorde con Hodder (1987: 10), un trabajo riguroso debe incluir el análisis de nuestro propio contexto como arqueólogos, en tanto el estudio del origen de nuestras propias ideas sobre el pasado puede sembrar dudas sobre su aplicabilidad. Hodder (1991:11) sostuvo que “... el objeto del pasado y el sujeto del presente se constituyen uno a otro en el proceso hermenéutico de interpretación”. A lo anterior, el autor agrega que las ideas de los arqueólogos pueden ser empleadas como parte de estrategias de dominación social en el presente. En la interpretación de vestigios de la guerra donde hay dos o más fuerzas encontradas y una se erige en vencedora, éste es un tema supremamente sensible; por ende, una perspectiva multivocal que contemple las voces de los afectados, los vencidos y los depositarios de la cultura material es indispensable. Con esto se pone de relieve el hecho de que todo conocimiento es político.

Otro elemento central en el postprocesualismo es el concepto de agencia, procedente de la sociología y adoptado por la arqueología en la década de 1980 como reacción al modelo procesual de sistemas. Los arqueólogos postprocesuales desean reconstruir la historia de actores que se construyen a sí mismos cultural y socialmente, sin estar necesariamente orientados por una necesidad biológica o una racionalidad económica. El concepto está íntimamente vinculado a la arqueología de género y al deseo de construir una arqueología autocrítica. De esta manera, los actores son reconocidos como sujetos informados y reflexivos con el poder de actuar, sin que sus acciones estén siempre determinadas por las condiciones circundantes. La agencia no es otorgada; es reclamada por los actores en el marco de unas condiciones sociales y culturales específicas (Barret, 2001: 141).

El interés en los símbolos y las ideas puede ser ejemplificado con un capítulo escrito por el arqueólogo establecido en Suecia, Fred Hocker (2011). Hocker, hoy director del museo del Vasa, es exalumno y exprofesor del Programa de Arqueología Náutica (NAP) de la Universidad de Texas A\&M. Curiosamente, el autor ofrece una perspectiva alternativa a la tendencia histórico-cultural que suele criticarse a los estudiosos de este programa académico, el primero y único en el mundo dedicado exclusivamente a la arqueología náutica.

En el capítulo titulado "El Barco de Guerra Simbólico", en su más reciente libro sobre el Vasa, Hocker muestra como la heráldica familiar y las figuras clásicas en el diseño del famoso buque resaltaban las virtudes del rey Gustavo Adolfo. Al retratar al mismo en compañía de figuras míticas e históricas, se 
pretendía legitimar su derecho al trono por encima de los reclamos de su primo, el rey Sigmund de Polonia. Una escultura de un noble polaco escondiéndose bajo una mesa simbolizaba la humillación, reforzada por el aplastante peso del ancla que recaía sobre la figura tallada bajo la serviola. Este símbolo había sido pensado para la tripulación, y la humillación se incrementaba aún más por el hecho de que la talla sólo podía ser apreciada mientras se estaba sentado en el jardín (nombre eufemístico que se daba a los baños de los buques). El autor explica que el barco era muy colorido y que sus colores también tenían una connotación simbólica. Por ejemplo, los ropajes reales estaban pintados de azul, el color más exclusivo, ya que son escasos los minerales y vegetales que ocurren naturalmente y contienen este color. Algunas tonalidades de azul halladas en las esculturas de la realeza del Vasa sólo podían alcanzarse empleando lapislázuli. Acorde con Hocker:

\begin{abstract}
...el lenguaje de las ideas tenía un vocabulario bien establecido en las esculturas, un vocabulario transmitido no solamente a través de la capacitación, sino también a través de libros de patrones. Una figura de un guerrero no era sólo una defensa. La posición en la que estaba parado, las ropas que vestía, las armas que llevaba y la forma en que las sostenía significaban algo específico. Estas imágenes eran una herramienta educativa útil para las amplias poblaciones iletradas de Europa y, aquellos con una educación clásica, habrían sido capaces de leer una gran cantidad de cosas en las tallas. Ideas complejas podían ser comunicadas si la composición era buena y los escultores talentosos (Hocker, 2011: 68, traducido por el autor).
\end{abstract}

En el caso de los estudios latinoamericanos, Del Cairo se ha referido a los mapas como armas simbólicas, con fines persuasivos y disuasivos, que permiten ejercer poder político (Del Cairo, 2013: 193). Su trabajo podría decirse cercano a la perspectiva postprocesual, pues además de su interés por los aspectos simbólicos de la cultura material, se ha esforzado por involucrar múltiples voces en el estudio y la gestión del Patrimonio Cultural Sumergido en Colombia. En este sentido, Del Cairo ha organizado múltiples encuentros de arqueólogos, miembros de la armada, la comunidad de buzos recreativos y las comunidades locales de la isla de Tierra Bomba, con miras a generar planes de protección e investigación de este patrimonio.

Desde la perspectiva del Manejo de Recursos Culturales, derivada de su carrera en la Universidad de Flinders en Australia y su más reciente posición en la Universidad de Carolina del Este, las palabras de McKinnon (2016:2, traducido por el autor) pueden ser utilizadas para ejemplificar la preocupación por la multivocalidad y el reconocimiento de la inherencia natural de la política en el discurso arqueológico. La autora afirma que: "La arqueología y el manejo del patrimonio son actos políticos y deben ser considerados como tales, particularmente cuando los sitios son interpretados y promovidos. Interpretar el patrimonio de tal forma en que no se privilegie una historia sobre otra o se trivialice la experiencia es crítico". A través de su artículo introductorio Underwater archaeology of a Pacific battlefield. The WWII battle of Saipan, McKinnon expone el proyecto y cubre temas tales como el Patrimonio de la Segunda Guerra Mundial y el Turismo, las comunidades depositarias, el entrenamiento, y el manejo. McKinnon sostiene que:

La arqueología de conflictos modernos, dado su interés en temas más recientes, es compleja pues forma parte de la memoria viva aún, y frecuentemente aquellos involucrados o afectados por el conflicto aún siguen vivos o sus familias están presentes. Adicionalmente, involucra tensiones políticas y sociales recientes y puede involucrar problemas éticos y sociales de luchas de poder y desigualdades. Esto hace que la investigación, interpretación y protección de estos sitios sea más difícil y sensible (McKinnon, 2016:2, traducido por el autor). 
McKinnon (2016: 1, traducido por el autor) afirma que "Decir arqueología subacuática del conflicto es diferente a decir arqueología del conflicto en tierra, es una declaración completamente errónea”. Por su parte y, quizás más acorde con la realidad actual de la arqueología subacuática de campos de batalla, Sabick \& Dennis (2011:4) sostienen que "los campos de batalla subacuáticos involucran una complejidad y unas bases metodológicas diferentes que los proyectos de arqueología que tiene lugar en tierra y emplean las técnicas tradicionales de prospección” (Sabick \& Dennis, 2011: 4, traducido por el autor). Sin embargo, McKinnon invita a observar el trabajo que hacen los arqueólogos terrestres con el propósito de comprender los asuntos relacionados con la arqueología de los conflictos modernos. Aún existe un trecho largo por recorrer antes de que los estudios arqueológicos de batallas navales alcancen los estándares de la arqueología terrestre de campos de batalla, pero ciertamente los alcances de esta última deben ser vistos como ejemplo a seguir.

Algunos conceptos militares readaptados a la arqueología por Scott \& McFeaters, son en cierta medida comparables con la categoría de "agencia”, en la medida en que sustentan la idea de que las fuerzas involucradas en un combate no están plenamente predestinadas o constreñidas por un sistema. Aunque como colectivo y no como individuos, una fuerza puede tener cierto grado de libertad y capacidad de alterar el curso de la batalla. Estos conceptos incluyen:

\begin{abstract}
...iniciativa, la habilidad de establecer o cambiar los términos de la batalla; agilidad, la habilidad que tienen las fuerzas amigables de reaccionar más rápido que el enemigo; profundidad, la extensión de las operaciones en tiempo, espacio, recursos y propósito; sincronización, la habilidad de concentrar recursos y actividades en el tiempo y en el espacio para proveer el máximo poder relativo de combate en un momento decisivo; y versatilidad, la habilidad de las unidades para enfrentar diversos retos, cambiar de enfoque, adaptar fuerzas, y moverse de un rol o misión a otro de manera rápida y eficiente (Scott \& McFeaters, 2011: 113, traducido por el autor).
\end{abstract}

Finalmente, incluso una influencia postprocesual puede detectarse en el trabajo más reciente de Martin, cuando refiere a los problemas hermenéuticos derivados del contexto en que están inmersos los investigadores. El autor sostiene que esto desencadena la imposibilidad de comprender una perspectiva de siglos pretéritos (Martin, 2001: 386).

El mayor aporte de los estudios postprocesuales a la arqueología de la guerra estriba en su dimensión ética. Su exhortación a las interpretaciones multivocales es la única vía para visibilizar y empoderar a los grupos locales, marginales y subalternos; y, en el caso específico de las confrontaciones bélicas, a los vencidos y a los depositarios de la cultura material del conflicto, cuyas voces rara vez son tenidas en cuenta desde otras perspectivas. Simultáneamente, una reflexión crítica sobre la posición desde la cual los arqueólogos interpretan el pasado da lugar a una arqueología autocrítica, que cuestiona su propia postura, habitualmente relacionada con instituciones hegemónicas.

\title{
CONCLUSIONES
}

A través de esta revisión bibliográfica se ha expuesto que los restos sumergidos de la guerra en períodos de tiempo diversos han sido estudiados por arqueólogos que tienden a ver el conflicto como una causa de cambio primordial. Inicialmente los estudios solían estar orientados a las naves y, con el tiempo, han incrementado su espectro y sus alcances para incluir escenarios de mayor tamaño, tales como los campos de batalla e, incluso, su contexto político. En los días tempranos, las excavaciones totales y la recuperación y 
conservación eran prácticas comunes, sostenidas por presupuestos que fueron reduciéndose a través del tiempo, lo que ha llevado a que la disciplina vire con rumbo a las excavaciones parciales y la preservación insitu - prácticas también soportadas por el deseo de dejar algo para las generaciones futuras de arqueólogos que gozarán de nuevas y más poderosas tecnologías.

De la mano de la reducción presupuestal y los cambios metodológicos que de ella derivan, las amenazas a los paisajes y vestigios de guerra remanentes se han incrementado por efecto de construcciones y buscadores de tesoros. Consecuentemente, la información adquirida mediante la prospección en sí misma ha cobrado gran importancia. La prospección permite ver más allá de los sitios particulares y arroja luz sobre áreas mucho más extensas. En el caso de la arqueología terrestre, la combinación de los SIG, los detectores de metales y la balística forense ha permitido investigar y plasmar en el paisaje movimientos individuales. En el registro arqueológico legado por unidades acuáticas aún es prácticamente imposible distinguir este tipo de movimientos, en la medida en que los movimientos tácticos de las naves (ataque y defensa) son el resultado de la acción colectiva. Adicionalmente, los investigadores están limitados por el tiempo que pueden permanecer bajo el agua, lo que convierte la detección sistemática de metales en áreas amplias en una práctica muy costosa y prolongada $\mathrm{y}$, simultáneamente, quizás no tan eficiente como lo es en tierra. Los estudios han demostrado que, hasta la fecha, y no obstante su enorme utilidad, la instrumentación geofísica subacuática de arrastre carece de la resolución que conduce al grado de detalle ya alcanzado en tierra. Aunque las herramientas empleadas por los arqueólogos subacuáticos no han cambiado sustancialmente, el almacenamiento digital, el incremento en la resolución y el procesamiento de la información por computador son desarrollos de gran importancia.

También se ha expuesto que la arqueología de los vehículos de guerra sumergidos ha seguido el camino la arqueología en general, moviéndose desde una perspectiva particularista histórico-cultural, a enfoques más recientes como el procesual y el postprocesual. El primero estuvo caracterizado por explicaciones del cambio basadas en la migración y la difusión; solía emplear fuentes documentales para describir el registro arqueológico; y, en ocasiones, se acompañó de cierto tono nacionalista.

El desarrollo teórico más relevante del procesualismo ha sido la insistencia en incrementar el enfoque de los sitios particulares a los campos de batalla, acompanado por la adopción de conceptos militares para analizar los patrones en el paisaje en busca de comportamientos en la guerra. Esta perspectiva también trajo consigo una apreciación más crítica de las fuentes escritas y una visión sistemática que considera el papel del medioambiente como forjador de los movimientos de guerra. Desde este enfoque también se ha abogado por la cientificidad de la arqueología y se ha insistido en la necesidad de formular hipótesis generales que puedan someterse a comprobación. La arqueología de los campos de batalla sumergidos tiene un enorme potencial, aunque requiere de nuevos avances tecnológicos y los conceptos que se aplican en tierra deben ser reconsiderados en la medida en que no aplican a los sitios acuáticos tan eficazmente como se pueden aplicar a los paisajes terrestres.

Finalmente, la perspectiva postprocesual ha enfatizado en los aspectos simbólicos de la guerra, en los problemas hermenéuticos y en las capacidades humanas de alterar los resultados de una batalla; pero aún más importante, ha puesto sobre la mesa discusiones éticas, como la importancia de considerar las voces de las comunidades depositarias en la interpretación y el manejo de los restos legados por la guerra. 
En lo que a los aspectos éticos atañe, el tratamiento de restos mortuorios derivados de un conflicto es un tema muy sensible. Sin embargo, si los restos son tratados con respeto y se atiende al marco regulatorio internacional, es posible adelantar investigaciones científicas rigurosas como lo demostraron los investigadores argentinos (Elkin et al., 2011: 313-319). Estos últimos consiguieron un acuerdo binacional con los británicos que no sólo les permitió efectuar estudios osteológicos y genealógicos, sino también dar lugar a la sepultura de los restos fúnebres, según las indicaciones y la participación de los depositarios de ese pasado.

La arqueología de campos de batalla debería moverse con rumbo a una síntesis pragmática, considerando los mayores logros de cada tendencia. Para tal fin, estos han sido sintetizados al finalizar cada uno de los apartados previos. Debe partirse de la descripción detallada de artefactos y pecios, para originar seriaciones, cronologías y tipologías. Luego debe moverse a explicaciones contextuales más comprensivas, sin olvidar la esfera ética implicada en estos objetos de estudio. Múltiples voces deben ser escuchadas e involucradas en la interpretación de la cultura material. El resultado de la práctica arqueología profesional es sólo una versión y debe ser autocrítico. No puede erigirse en estrategia para la subordinación de minorías; al contrario, debe abogar porque éstas sean empoderadas en la interpretación y gestión del patrimonio del conflicto. Los relatos deben enfatizar en las terribles consecuencias de la guerra e invitar a las gentes a que eviten participar en futuros conflictos, en vez de urgirles a que formen parte de ellos.

\section{AGRADECIMIENTOS}

Agradezco a los profesores Alston Thoms y Filipe Castro de la Universidad de Texas A\&M por sus valiosos comentarios y correcciones al manuscrito. Agradezco también a Phil Watson por la edición de la primera versión de este documento que originalmente fue escrito en inglés, y al Dr. Antonio Jaramillo por su traducción del resumen al portugués. Finalmente, estoy muy agradecido por las críticas constructivas del primer y el tercer revisor del documento, pues gracias a estas el trabajo mejoró sustancialmente. 
REFLEXIONES CRÍTICAS SOBRE LOS ABORDAJES TEÓRICO-METODOLÓGICOS EN LA ARQUEOLOGÍA

DE BUQUES DE GUERRA Y CAMPOS DE BATALLA ACUÁTICOS

\section{REFERENCIAS BIBLIOGRÁFICAS}

ALCALÁ-ZAMORA, J. N. 2004. La empresa de Inglaterra: (la "Armada invencible": fabulación y realidad). Real Academia de la Historia, Madrid.

ARNOLD, W. S. 2016. Whatever Works: Amphibious Tractors and Field Expedient Armor Modifications. In: McKINNON, J \& CARRELL, T (eds.) Underwater Archaeology of a Pacific Battlefield: The WWII Battle of Saipan. Springer, New York. Pp. 49-62.

BARRET, J.C. 2001. Agency, the duality of structure, and the problem of the archaeological record. In: HODDER, I (ed.) Archaeological Theory Today. Cambridge University Press, Cambridge. Pp: 141-164

BELL, S. 2016. In the Drink: Sunken Aircraft of the Battle of Saipan. In: McKINNON, J \& CARRELL, T (eds.) Underwater Archaeology of a Pacific Battlefield: The WWII Battle of Saipan. Springer, New York. Pp. 39-48.

BINFORD, L. R. 1965. Archaeological Systematics and the Study of Culture Process. American Antiquity. Vol. 31, No. 2: 203-210.

BOUND, M. (ed.). 1995. The Archaeology of Ships of War. Anthony Nelson, Oswestry.

BOUND, M. (ed.). 1998a. Excavating Ships of War. Anthony Nelson, Oakville, CT.

BOUND, M. 1998 b. Lost ships: the discovery and exploration of the ocean's sunken treasures. Simon \& Shuster Editions, New York.

BOUND, M. \& BADO, H. 1998. Nelson's Agamemnon. In: BOUND, M. (ed.). 1998. Excavating Ships of War. Anthony Nelson, Oakville, CT.

BROADWATER, J. D. 2011. Naval Battlefields as Cultural Landscapes. The Siege of Yorktown. In: GEIER, C.R., BABITS, L.E., SCOTT, D. \& ORR, D.G. (eds.) Historical Archaeology of Military Sites. Texas A\&M University Press, College Station. Pp.177-187

CARABIAS, D. 2008. Enfoques metodológicos integradores en arqueologia maritima: Contribuciones a la compresión del Paisaje Cultural Maritimo de la Patagonia Occidental en el Siglo XVIII a partir del estudio de la fragata Wager. Ponencia presentada en el V Congreso de Arqueología de Colombia. Patrimonio Paisaje y Sociedad. Universidad de Antioquia, Medellin, Colombia. 19-22 de noviembre de 2008.

CARABIAS, D. 2009. Naufragio del HMS Wager en la Patagonia. Encuentro de dos mundos. Productora Gráfica MC4, Chile.

CARAbias, D., SimonetTi, R. MORAleS, C., LETElier, D., ASPIllaga, E., RETAmal, R. 2013. Informe de Peritaje Arqueológico Subacuático, Monumento Histórico Corbeta Esmeralda, Comuna de Iquique, I Región de Tarapacá. ARKA: Valparaíso, Chile.

CARABIAS, D., SIMONETTI, R., MORALES, C. 2018. Exploring Infatigable (1855): First insights from Archaeology into the mid-Nineteenth Century Chilean Navy. Ponencia presentada en Society for Historical Archaeology Conference, New Orleans, Estados Unidos.

CASADO SOTO, J. L. 1988. Los barcos españoles del siglo XVI y la Gran Armada de 1588. Editorial San Martín, Madrid.

CASSON, L. \& STEFFY, J. R. (eds.). 1991. The Athlit Ram. Texas A\&M University Press, College Station.

CEDERLUND, C.O. 1985. Shipbuilding in the 17th and 18th Centuries: The Wasa as a product of Dutch Shipbuilding. In: BANG-ANDERSEN, A., GREENHILL, B. \& GRUDE, E.H. The North Sea. A Highway of Economic and Cultural Exchange. Norwegian University Press and Oxford University Press, Stavanger. Pp. 167-78.

CEDERLUND, C. O. 2006. Vasa I. The Archaeology of a Swedish Warship of 1628. National Maritime Museums of Sweden, Stockholm. 
COHN, A.B., KANE, A.I., SABICK, C. R., SCOLlON, E. R. \& ClEMENT, J. B. 2007. Valcour Bay Research Project: 1999-2004 Results from the Archaeological Investigation of a Revolutionary War Battlefield in Lake Champlain, Clinton County, New York. Lake Champlain Maritime Museum, New York.

CONLIN, D. \& RUSSELL, M. 2006. Archaeology of a Naval Battlefield: H. L. Hunley and USS Housatonic. IJNA. Vol. 35, No.1: 20-40

CONLIN, D. \& RUSSELL, M. 2011. Maritime Archaeology of Naval Battlefields. In: GEIER, C.R., BABITS, L.E., SCOTT, D. \& ORR, D.G. (eds.) Historical Archaeology of Military Sites. Texas A\&M University Press, College Station. Pp.39-56.

DEL CAIRO H., C. 2009. Arqueología de la guerra en la Bateria de San Felipe. Editorial CESO - Universidad de los Andes, Bogotá

DEL CAIRO H., C. 2013. Mentiras verdaderas o la topología de la guerra. Aproximación arqueológica a la cartografía colonial de Bocachica, Cartagena de Indias. Apuntes: Revista de Estudios sobre Patrimonio Cultural. Vol.26, No. 1: 186-203.

DELGADO, J. P. 1991. The significance of the sunken vessels of operation crossroads. In: DELGADO, LENIHAN \& MURPHY (eds.). The archaeology of the atomic bomb: A submerged cultural resources assessment of the sunken fleet of operation crossroads at Bikini and Kwajalein Atoll lagoons. Southwest Cultural Resources Center Professional Papers Number, Santa Fe, New Mexico. Pp. 143-162

DELGADO, J.P. 2001. Lost Warships: An Archaeological Tour of War at Sea. Douglas and Mclntyre, Vancouver

ELKIN, D, MURRAY, C., BASTIDA, R., GROSSO, M., ARGÜESO, A., VAINSTUB, D., UNDERWOOD, C., CIARLO, N. 2011. El naufragio de la HMS Swift (1770): Arqueología marítima en la Patagonia. Vazquez Mazzini Editores, Buenos Aires.

FLANNERY, K. V. 1968. Archaeological Systems Theory and Early Mesoamerica. In: MEGGERS, B. J. (ed.). Anthropological Archaeology in the Americas. Washington, Anthropological Society of Washington. Pp. 67-87.

GEIER, C.R. \& POTTER S. R. (eds.). 2000. Archaeological perspectives of the American Civil War. Florida University, Gainesville.

GOULD, R.A. 2011. Archaeology and the Social History of Ships. 2 ed. Cambridge University Press, New York.

GROSSO, M. 2014. Post-depositional processes studies of wooden artifacts from the 18th century Swift shipwreck site (Patagonia, Argentina). Intersecciones en Antropología. Vol. 15: 55-70.

GUEDES, M. 1981. A study of some nautical instruments (including two astrolabes) recovered from the Sacramento shipwreck (1668) at Bahia. In: HOWSE. (ed.). Five hundred years of Nautical Science 1400-1900. National Maritime Museum, Greenwich.

GUILMARTIN, J. 1982. The Cannon of the Batavia and the Sacramento: early modern cannon founding reconsidered. The International Journal of Nautical Archaeology and Underwater Exploration. Vol. 11, No.2: 133144.

GUILMARTIN, J., 1983. The Guns of the Santíssimo Sacramento. Technology and Culture. No. 24: 559-601.

GUZMAN, J. 2017. Cañón de Cañones. Arqueología de un accidente naval británico de finales del siglo XVIII en la Sonda de Campeche. Tesis de Licenciado en Arqueología. Universidad de Autónoma de Zacatecas, Zacatecas.

JOHNSEN, H. \& OLSEN, B. 1992. Hermeneutics and Archaeology: On the Philosophy of Contextual Archaeology. American Antiquity. Vol. 57, No. 3: 419-436

KIMURA, J., STANIFORTH, M., LIEN, L.T. \& SASAKI, R. 2013. Naval Battlefield Archaeology of the Lost Kublai Khan Fleets. INJA. Vol. 43. No. 1: 76-86

HANKS, M. 2016. Landing at Saipan: The Three M4 Sherman Tanks That Never Reached the Beach. In: McKINNON, J \& CARRELL, T (eds.) Underwater Archaeology of a Pacific Battlefield: The WWII Battle of Saipan. Springer, New York. Pp. 63-71. 
HILDRED, A. 2011. Weapons of Warre: The Armaments of the Mary Rose, The Archaeology of the Mary Rose. Mary Rose Trust, United Kingdom.

HOCKER, F. 2011. Vasa: A Swedish Warship. Medstroms Bokforlag, Sweden.

HODDER, I. 1987.The Contextual Analysis of Symbolic Meanings. In: HODDER I. (ed.) The Archaeology of Contextual Meanings. Cambridge University Press, Cambridge. Pp. 1-10.

HODDER, I. 1991. Interpretive Archaeology and Its Role. American Antiquity. Vol. 56, No. 1: 7-18

HODDER, I. 2008. Multivocality and Social Archaeology. In: HABU J., FAWCETT C. \& MATSUNAGA J.M. (eds.) Evaluating Multiple Narratives. Springer, New York.

LANDA, C.G. 2013. Arqueología de campos de batalla en Latinoamérica: apenas un comienzo. Arqueología. Vol. 19, No. 2: 265-286.

MANDERS, M.R. \& BROUWERS, W.F.G. (eds.) 2016. The Utrecht. A shipwreck of the Dutch admiralty in the Baía de Todos os Santos, Brazil: its history from battle to archaeological assessment. Cultural Heritage Agency of the Netherlands, Amersfoort.

MARSDEN, P. 2003. Sealed by Time: The Loss and Recovery of the Mary Rose, The Archaeology of the Mary Rose. Mary Rose Trust, United Kingdom.

MARTIN, C. 1975. Full fathom five: wrecks of the Spanish Armada. Viking Press, New York.

MARTIN, C. 1994. Incendiary weapons from the Spanish Armada wreck La Trinidad Valencera, 1588. IJNA. Vol. 23, No.3: 207-217

MARTIN, C. 2001. De-Particularizing the Particular: Approaches to the Investigation of Well-Documented PostMedieval Shipwrecks. World Archaeology. Vol. 32, No. 3: 383-399

McKinNON, J. \& CARREL, T. L. (eds.). 2016. Underwater Archaeology of a Pacific Battlefield: The WWII Battle of Saipan. Springer, New York.

McKINNON, J. 2016. Underwater Archaeology of a WWII Battlefield. In: McKINNON, J \& CARRELL, T (eds.) Underwater Archaeology of a Pacific Battlefield: The WWII Battle of Saipan. Springer, New York.

MUCKELROY, K. 1978. Maritime Archaeology. Cambridge University Press, New York.

NASTI, A. 2001. Recovery and conservation of navigational instruments from the Spanish troopship Salvador which sank in 1812 in Maldonado Bay, Punta del Este, Uruguay. IJNA. Vol. 30, No. 2:279-281.

NASTI, A. 2008. Aportes de la arqueología subacuática: el naufragio de la fragata española San Salvador (1812). Temas de historia argentina y americana. No.13: 153-163.

NETO, U. 1977. “O Galeão Sacramento (1668): Um naufrágio no século XVII e os resultados de uma pesquisa de arqueologia submarina na Bahia/Brasil.” Revista Navigator. No. 13.

NETO, U. 1979. The Shipwreck of the galleon Sacramento1668 off Brazil. International Journal of Nautical Archaeology and Underwater Exploration. Vol. 8. No. 3: $211-223$.

RIVOlTA, M.C., MONTENEGRO, M., MENEZES FERREIRA, L. \& NASTRI, J. (eds.) 2014. Multivocalidad y activaciones patrimoniales en arqueología: perspectivas desde Sudamérica. Fundación de Historia Natural Félix de Azara, Buenos Aires.

ROSE, K. 2014 The Naval Architecture of Vasa, a 17th-Century Swedish Warship. Dissertação (Doutorado em Antropologia). Texas A \& M University, College Station.

SABICK, C. \& DENNIS, J. 2011. Submerged Battlefield Protection Manual. Lake Champlain Maritime Museum, New York.

SCHIFFER, M.B. 1976. Behavioral Archeology. Academic Press, New York. 
SCHIFFER, M.B. 1987. Formation Processes of the Archaeological Record. University of New Mexico Press, Albuquerque.

SCHIFFER, M.B. 2010. Behavioral Archaeology: Principles and Practice. Equinox, London.

SCHIFFER, M.B. 2011. Studying Technological Change: A Behavioral Approach. University of Utah Press, Salt Lake City.

SCOTT, D. 2005. Entrevista: The Archaeology of Battlefields. In: Archaeology. Archaeological Institute of America. Disponível em: http://archive.archaeology.org/online/interviews/scott.html. Acesso em: Abril 12 de 2017.

SCOTT, D. \& McFEATERS, A. 2011. The Archaeology of Historic Battlefields: A History and Theoretical Development in Conflict Archaeology. Journal of Archaeological Research. Vol. 19:103-132

SCOTT, D. WILlEY, P. \& CONNOR, M. 1998. They Died With Custer: The Soldiers' Skeletons From The Battle of the Little Bighorn. University of Oklahoma Press, Norman.

SCOTT, D. \& FOX, R. 1987. Archeological Insights into the Custer Battle: A Preliminary Assessment. University of Oklahoma Press, Norman.

SCOTT, D. FOX, R., CONNOR, M. \& HARMON, D. 1989. Archaeological Perspectives on the Battle of the Little Bighorn. University of Oklahoma Press, Norman.

SMITH, T. 2004. Plane Sailing: The archaeology of aircraft losses over water in New South Wales, Australia. Bulletin of the Australasian Institute for Maritime Archaeology. Vol. 28: 111-122

SUTHERLAND, T. \& HOLST, M. 2005 Battlefield Archaeology: A Guide to the Archaeology of Conflict. British Archaeological Jobs Resource (BAJR), London.

TORRES, R. \& CASTRO, F. 2012. The Utrecht Shipwreck Research Effort. Preliminary Report and Artifact Catalogue. Mutual Heritage Program RCE, Netherlands and Nautical Archaeology Program Texas A\&M University, College Station.

TRIGGER, B. 1996. A History of Archaeological Thought. Cambridge University Press, New York.

VENCL, S. 1984. War and Warfare in Archaeology. Journal of Anthropological Archaeology. Vol. 3: 116-132.

WITZEN, N. 1671. Aaloude en hedendaagsche scheeps-bouw en bestier. Architectura navalis et regimen nauticum. Pieter and Joan Blaeu, Amsterdam. 